\title{
A kinetic study on the conversion of cis-2-butene with deuterium on a $\mathrm{Pd} / \mathrm{Fe}_{3} \mathrm{O}_{4}$ model catalyst
}

\author{
Wiebke Ludwig, Aditya Savara, Björn Brandt and Swetlana Schauermann*
}

\author{
Received 31st March 2010, Accepted 12th October 2010 \\ DOI: $10.1039 / \mathrm{c0cp00078g}$
}

The conversion of cis-2-butene with deuterium over a well-defined $\mathrm{Pd} / \mathrm{Fe}_{3} \mathrm{O}_{4}$ model catalyst was studied by isothermal pulsed molecular beam (MB) experiments under ultra high vacuum conditions. This study focuses on the processes related to dissociative hydrogen adsorption and diffusion into the subsurface of Pd nanoparticles and their influence on the activity and selectivity toward competing cis-trans isomerization and hydrogenation pathways. The reactivity was studied both under steady state conditions and in the transient regime, in which the reaction takes place on a D-saturated catalyst, over a large range of reactant pressures and reaction temperatures. We show that large olefin coverages negatively affect the abundance of $\mathrm{D}$ species, as indicated by a reduction of both reaction rates under steady state conditions as compared to the transient reactivity on the catalyst pre-saturated with $\mathrm{D}_{2}$. Limitations in $\mathrm{D}$ availability during the steady state lead to a very weak dependence of both reaction rates on the olefin pressure. In contrast, when the surface is initially saturated with $\mathrm{D}$, the transient reaction rates of both pathways exhibit positive kinetic orders on the butene pressure. Cis-trans isomerization and hydrogenation show kinetic orders of +0.7 and +1.0 on the $\mathrm{D}_{2}$ pressure, respectively. Increasing availability of $\mathrm{D}$ noticeably shifts the selectivity toward hydrogenation. These observations together with the analysis of the transient reaction behavior suggest that the activity and selectivity of the catalyst is strongly controlled by its ability to build up and maintain a sufficiently high concentration of $\mathrm{D}$ species under reaction conditions. The temperature dependence of the reaction rates indicates that higher activation energies are required for the hydrogenation pathway than for the $c i s-$ trans isomerization pathway, implying that different rate limiting steps are involved in the competing reactions.

\section{Introduction}

The conversion of olefins with hydrogen over transition metal surfaces is one of the most important reactions employed in industrial processes and catalysis research. ${ }^{1-6}$ These reactions have attracted much attention in studies on well-defined surfaces of single crystals ${ }^{4,5,7}$ and supported metal nanoparti$\operatorname{cles}^{8-11}$ in order to achieve a better molecular understanding of the processes governing the activity and selectivity of the catalyst. Recently, several examples of catalytic systems were described in the literature where hydrogenation of the olefinic double bond was shown to crucially depend on the presence of hydrogen species absorbed in the subsurface region of a metal catalyst. $^{8-12}$ Despite this recent progress, a complete microscopic understanding of the phenomena controlling the activity and selectivity in olefin conversions is still missing. Particularly, classical ambient-pressure catalytic studies report reaction orders in olefin pressure that are typically close to zero both for isomerization and hydrogenation ${ }^{3,5,13-19}$ and reaction orders close to one in hydrogen pressure. ${ }^{3,5,15-20}$ At present, only a limited understanding of the origin of these macroscopic observations and of the rate determining steps is available.

Fritz-Haber-Institut der Max-Planck-Gesellschaft, Faradayweg 4-6, 14195 Berlin, Germany.E-mail: schauermann@fhi-berlin.mpg.de
According to the generally accepted Horiuti-Polanyi reaction mechanism, ${ }^{21}$ olefin conversions over transition metal catalysts proceed via a series of consecutive hydrogenation and dehydrogenation steps. In the case of $c i s$-2-butene, a 2-butyl- $d_{1}$ intermediate is formed in the first half-hydrogenation step (see Fig. 1a), which is a common reaction intermediate for both the cis-trans isomerization and the hydrogenation reaction pathway. ${ }^{5,21,22}$ The butyl intermediate can undergo $\beta$-hydride elimination resulting in either $c i s$-2-butene (the original molecule) or trans-2-butene- $d_{1}$ (a cis-trans isomerized molecule). When $\mathrm{D}_{2}$ is used as a reactant, each cis-trans isomerization event is accompanied by substitution of one hydrogen atom with a deuterium, ${ }^{23}$ allowing for a distinction between the reactant $\mathrm{cis}$ 2-butene and the product trans-2-butene- $d_{1}$ in the gas phase by mass spectrometry. Alternatively, a second hydrogen (deuterium) atom can be inserted into the carbon metal bond of the 2-butyl- $d_{1}$ intermediate, hydrogenating the molecule to butane- $d_{2}$. Dehydrogenation of the adsorbed alkene as well as the butyl- $d_{1}$ species may also occur, yielding alkylidynes and other partly dehydrogenated carbonaceous deposits which remain strongly adsorbed on the surface. ${ }^{24,25}$

Alkene conversions with hydrogen have been investigated previously both on single crystal surfaces ${ }^{4,5,12,26,27}$ and on oxide supported metal nanoparticles. ${ }^{8-10,28-32}$ Remarkably high overall reaction probabilities of up to 0.2 were observed for the Pd nanoparticles, while typical values reported on realistic 


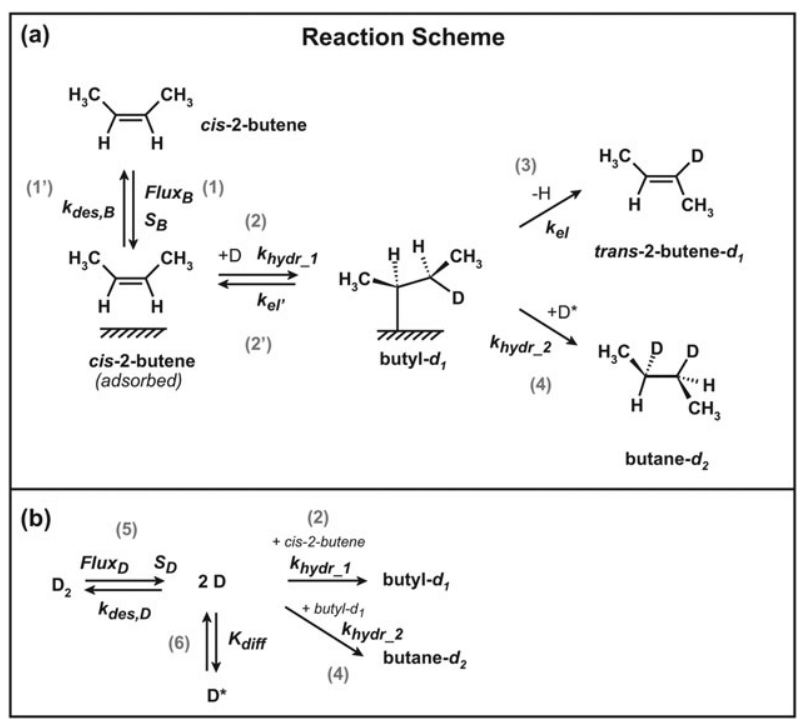

Fig. 1 (a) Schematic representation of cis-2-butene conversion with $\mathrm{D}_{2}$ on a Pd model catalyst: (1) molecular adsorption of the olefin, (2) first half-hydrogenation step of cis-2-butene to butyl- $d_{1}$, (3) cis-trans isomerization to butene- $d_{1}$ proceeding through consecutive rotation and $\beta$-hydride elimination, (4) hydrogenation involving a second-half hydrogenation step of butyl- $d_{1}$ to butane- $d_{2}$. Additionally, partial dehydrogenation of the adsorbed olefin species takes place resulting in the formation of different hydrocarbon species. (b) Schematic representation of $\mathrm{D}_{2}$ conversion on a $\mathrm{Pd}$ catalyst: (5) dissociative adsorption of $\mathrm{D}_{2}$ on the surface of Pd particles, (6) reversible D diffusion into the subsurface region. Additionally, D is consumed in the reaction steps (2) and (4) depicted in (a).

catalytic systems around room temperature and under atmospheric pressures reach probabilities on the order of $10^{-3}-10^{-8} \cdot 3,5$

One of the most important conclusions of these studies is that the distribution and population of hydrogen atoms in different adsorption states, such as adsorbed on the surface and absorbed in the subsurface region of $\mathrm{Pd}$ nanoparticles, is crucial to the control of the activity and selectivity of the catalyst. At reaction temperatures below $210 \mathrm{~K}$, saturation of the surface by hydrocarbons limits hydrogen dissociation and thereby suppresses both isomerization and hydrogenation activity under steady state reaction conditions. This limitation vanishes above $220 \mathrm{~K}$, where sustained isomerization evidences facile hydrogen dissociation on the surface. The presence of only $\mathrm{H}$ on the surface of the $\mathrm{Pd}$ nanoparticles was shown, however, to be insufficient for hydrogenation. Here, the crucial role of $\mathrm{H}$ species absorbed in the near surface region of the $\mathrm{Pd}$ nanoparticles was demonstrated by a combination of $\mathrm{H}$-depth profiling via nuclear reaction analysis (NRA) and transient molecular beam experiments. ${ }^{9,10}$ It remains unclear if the subsurface $\mathrm{H}$ species directly attack the butyl species or if they only modify the properties of the surface species, making surface $\mathrm{H}$ atoms more prone to attack the metal-carbon bond.

The hydrogenation activity of the $\mathrm{Pd}$ catalyst and the associated population of subsurface hydrogen species were both found to be closely connected to the presence of carbon on the Pd catalyst. ${ }^{9,10}$ Thus, pristine Pd nanoparticles presaturated with $H(D)$ show initially high reactivity in hydrogenation but cannot maintain it under steady state reaction conditions presumably due to limited replenishment of subsurface H(D) species. ${ }^{9-32}$ In contrast, when particles are modified by deposition of carbon, which decorates only a small fraction of the particle's surface - the low-coordinated edge and corner sites ${ }^{30}$ - hydrogenation can proceed also under the steady state conditions indicating fast refilling of the subsurface $\mathrm{H}(\mathrm{D})$ reservoir. It has to be noted that carbon deposition does not enhance the hydrogenation rate as compared to the initial reaction rate on the $\mathrm{D}$-saturated $\mathrm{Pd}$ nanoparticles but solely allows for maintaining it at the initially high level under steady state conditions. This unusual promotion of sustained hydrogenation activity by carbonaceous deposits was attributed to easier $\mathrm{H}(\mathrm{D})$ diffusion into the subsurface region of Pd nanoparticles based on both experimental NRA results ${ }^{9}$ and theoretical calculations. ${ }^{33}$ Briefly, co-adsorbed carbon was found to reduce the $\mathrm{H}$ adsorption energy on the surface of $\mathrm{Pd}$ particles and to expand the Pd lattice; both effects lead to a substantial decrease or even a vanishing of the activation barrier for $\mathrm{H}$ diffusion into the subsurface region of $\mathrm{Pd}$ nanoparticle (henceforth called "subsurface diffusion").

In view of these recent results identifying hydrogen dissociation and subsurface diffusion on metal nanoparticles as key reaction steps for the overall activity and selectivity, it is important to understand how particular reaction conditions (such as reactant pressures, their relative ratios and the reaction temperature) influence these two hydrogen-related processes and consequently the overall reactivity. In this study, we investigate the influence of these reaction conditions on $\mathrm{cis}$-2butene conversion with deuterium over $\mathrm{Pd}$ nanoparticles supported on a model $\mathrm{Fe}_{3} \mathrm{O}_{4} / \mathrm{Pt}(111)$ film — both under steady state and transient conditions. For this we apply pulsed molecular beam techniques, which allow us to directly compare the initial reactivity on D-saturated surfaces with that obtained under steady state reaction conditions. In the following, the time period between the beginning of the olefin pulse and the establishing of the steady state conditions will be denoted as the transient regime. This regime is characterized by a high availability of atomic $\mathrm{D}$ provided by re-saturation of the surface with $\mathrm{D}_{2}$ in the absence of the olefin supply. The direct comparison of the reactivities on the D-saturated surface and the surface under the steady state conditions is enabled by the use of two independent sources: a continuous $\mathrm{D}_{2}$ and a pulsed cis-2-butene molecular beam. Two typical responses of the catalytic system can be obtained upon modulation of the olefin beam (Fig. 2): ${ }^{30,31}$ first, the reactivity under the steady state conditions can remain the same as at the beginning of the olefin pulse (Fig. 2a). In this case, no significant limitations in D availability are induced by additionally co-adsorbed hydrocarbons during the butene exposure. Second, the reactivity in the steady state can drop to a significantly lower level as compared to the transient regime (Fig. 2b). In this case the reaction takes place in the steady state under D-deficient conditions and is limited by the formation of surface or/and subsurface D species. Thus, the form of the product response curve upon modulation of the olefin beam provides unique information on possible involvement of hydrogen-related processes in the rate-determining steps. Using such an approach, we investigated the influence of different reaction 


\section{averaged pulse profiles}

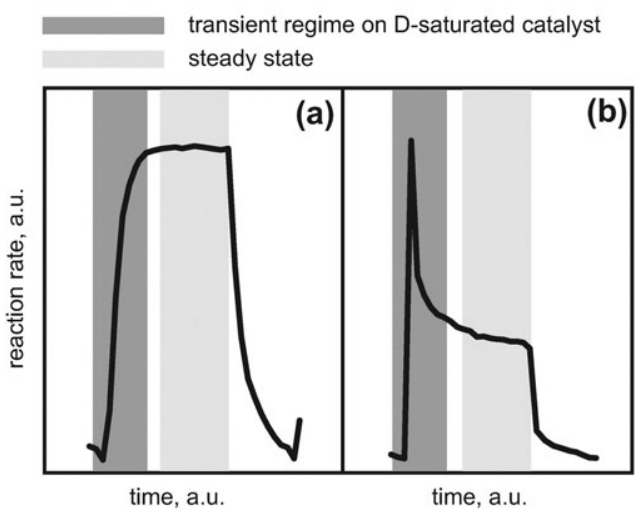

Fig. 2 Typical product response curves obtained with a continuously running $\mathrm{H}_{2}\left(\mathrm{D}_{2}\right)$ beam and a modulated olefin beam ${ }^{31}$ under the hydrogen-rich (a) and hydrogen-deficient (b) conditions. In the transient regime upon modulation of olefin beam, for both cases no limitations in H(D) availability either on the surface or in subsurface for both cases are present. Under steady state conditions, the reactivity remains the same under hydrogen-rich conditions (a) or drops to a lower level under $\mathrm{H}$-deficient conditions (b) due to limited formation of surface or/and subsurface $\mathrm{H}$ species.

parameters - the reactant fluxes, their relative ratios and the reaction temperature - on the role of hydrogen-related processes in the overall reactivity.

\section{Experimental}

All molecular beam experiments were performed at the FritzHaber-Institut (Berlin) in a UHV apparatus described in detail elsewhere. $^{34} \mathrm{~A}$ schematic representation of the setup is displayed in Fig. 3a. In brief, the setup allows for simultaneously directing up to three molecular beams on the sample surface. An effusive doubly-differentially-pumped multi-channel array source was employed to provide $\mathrm{D}_{2}$. Remote-controlled shutters and valves were used for modulation of this beam. In these experiments, beam intensities for $\mathrm{D}_{2}$ ranged from 0.35 to $4.2 \times 10^{15}$ molecules $\mathrm{cm}^{-2} \mathrm{~s}^{-1}$ (from 0.4 to $5.3 \times 10^{-6}$ mbar). The beam diameter was selected such that it exceeded the sample diameter. A supersonic beam, generated by a triply-differentially-pumped source and modulated by a solenoid valve and a remote-controlled shutter, was used to dose cis-2-butene (Aldrich, >99\%).

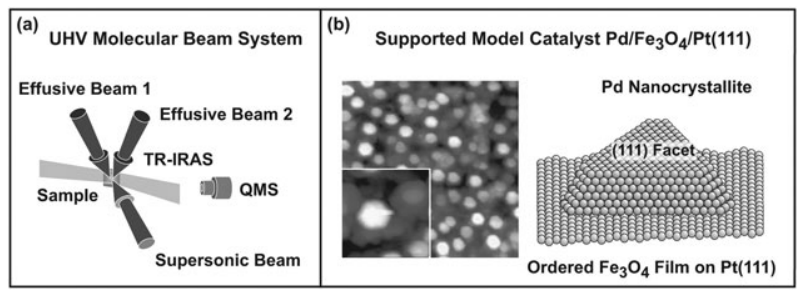

Fig. 3 (a) Schematic of molecular beam system; (b) scanning tunnelling microscopy (STM) image $(100 \mathrm{~nm} \times 100 \mathrm{~nm}$, inset: $20 \mathrm{~nm}$ $\times 20 \mathrm{~nm}$ ) of the $\mathrm{Pd} / \mathrm{Fe}_{3} \mathrm{O}_{4} / \mathrm{Pt}(111)$ supported model catalyst used in the experiments described here, together with a schematic representation of the structure of the Pd nanoparticles (from ref. 35).
A chopper wheel allowing for three settings was used to vary the butene beam intensity from 2.5 to $84.8 \times 10^{12}$ molecules $\mathrm{cm}^{-2} \mathrm{~s}^{-1}\left(1.2-40.9 \times 10^{-8}\right.$ mbar, typical backing pressure: 1.2 bar). In all experiments discussed here, the diameter of the butene beam was chosen to be smaller than the sample. An automated quadrupole mass spectrometer (QMS) system (ABB Extrel) was employed for the continuous and simultaneous monitoring of the partial pressures of the reactants (cis-2-butene, determined by the signal of the $\mathrm{C}_{3} \mathrm{H}_{5}{ }^{+}$fragment at 41 a.m.u. because of experimental reasons) and products (trans-2-butene- $d_{1}$, $\mathrm{C}_{3} \mathrm{H}_{4} \mathrm{D}^{+}$fragment at 42 a.m.u.; cis-2-butene- $d_{2}, \mathrm{C}_{3} \mathrm{H}_{3} \mathrm{D}_{2}{ }^{+}$ fragment at 43 a.m.u.; butane- $d_{2}, \mathrm{C}_{3} \mathrm{H}_{5} \mathrm{D}_{2}{ }^{+}$fragment at 45 a.m.u., and butane- $d_{3}$ ). All QMS data have been corrected to account for the natural abundance of ${ }^{13} \mathrm{C}$.

$\mathrm{The} \mathrm{Pd} / \mathrm{Fe}_{3} \mathrm{O}_{4}$ model catalyst was prepared by growing a thin ( $\sim 100 \AA$ ) $\mathrm{Fe}_{3} \mathrm{O}_{4}$ film on a $\mathrm{Pt}(111)$ single crystal by repeated cycles of $\mathrm{Fe}$ ( $>99.99 \%$, Goodfellow) physical vapor deposition and subsequent oxidation (see ref. 35-38 for details). The cleanliness and quality of the oxide film was checked by IRAS of adsorbed CO and by LEED. Pd particles ( $>99.9 \%$, Goodfellow) were grown by physical vapor deposition using a commercial evaporator (Focus, EFM 3, flux calibrated by a quartz microbalance) while keeping the sample temperature at $115 \mathrm{~K}$. During metal evaporation the sample was biased to avoid formation of defects by metal ions. The Pd coverage used to prepare the particles was $2.7 \times 10^{15}$ atoms $\mathrm{cm}^{-2}$. The particles were subsequently annealed to $600 \mathrm{~K}$ and stabilized by repeated cycles of oxygen $\left(8 \times 10^{-7} \mathrm{mbar}\right.$ for $\left.1000 \mathrm{~s}\right)$ and $\mathrm{CO}$ $\left(8 \times 10^{-7}\right.$ mbar for $\left.3000 \mathrm{~s}\right)$ exposures at $500 \mathrm{~K}$ before use. ${ }^{35} \mathrm{An}$ STM image of the model catalyst obtained from this preparation method is shown in Fig. 3b. The surface displays $\mathrm{Pd}$ particles with an average diameter of $7 \mathrm{~nm}$ containing approximately 3000 atoms each. The particles uniformly cover the support with an island density of about $8.3 \times 10^{11}$ islands $\mathrm{cm}^{-2} 35$ The majority of the particles are well-shaped crystallites grown in the (111) orientation and terminated predominantly by $(111)$ facets $(\sim 80 \%)$ as well as by a small fraction of (100) facets $(\sim 20 \%)$.

Before each experiment, the $\mathrm{Pd} / \mathrm{Fe}_{3} \mathrm{O}_{4}$ model catalyst was cleaned by oxidation-reduction cycles as employed during stabilization of the Pd particles. Subsequently, the model catalyst was precovered with carbon. For carbon precovering, the sample was exposed to $280 \mathrm{~L} \mathrm{D}_{2}$ and $0.8 \mathrm{~L}$ cis-2-butene at 100 $\mathrm{K}$ and heated in vacuum to $500 \mathrm{~K}$ in the following (see ref. 30 for details). Isothermal experiments were performed directly after carbon precovering.

\section{Results and discussion}

\subsection{Dependence on the $D_{2}$ flux}

First, we investigate the influence of the deuterium pressure on the cis-trans isomerization and hydrogenation rates of cis-2butene over $\mathrm{Pd}$ nanoparticles supported on a $\mathrm{Fe}_{3} \mathrm{O}_{4} / \mathrm{Pt}(111)$ model film. In all experiments reported here, $\mathrm{Pd}$ particles were pre-covered with small amounts of carbonaceous species following a well-established procedure ${ }^{31}$ in order to enable sustained reactivity for both pathways (cis-trans isomerization 


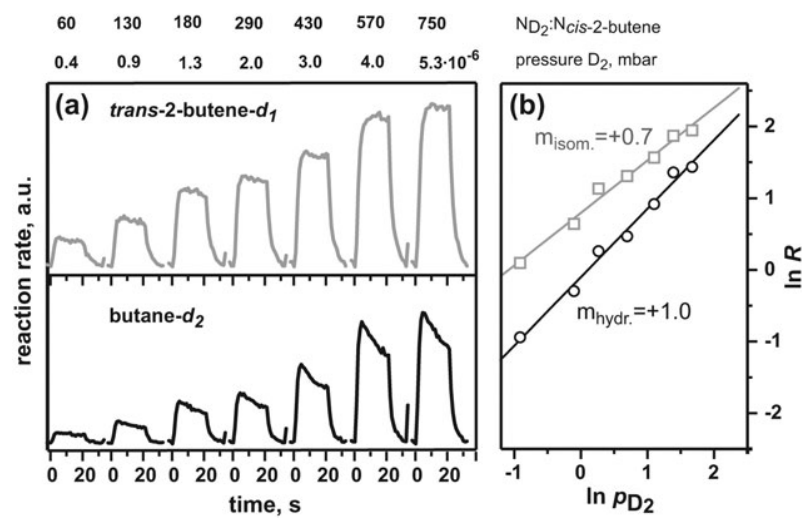

Fig. 4 (a) Averaged reaction rates as a function of time obtained for the cis-trans isomerization (grey traces, product trans-2-butene- $d_{1}$ ) and hydrogenation (black traces, product butane- $d_{2}$ ) pathways from a series of pulsed molecular beam experiments, in which the catalyst was exposed to a continuous $\mathrm{D}_{2}$ molecular beam and a modulated cis-2butene molecular beam. The results are shown for experiments conducted at different $\mathrm{D}_{2}$ pressures $\left(0.4-8.0 \times 10^{-6} \mathrm{mbar}\right)$ and at a constant cis-2-butene pressure $\left(2.7 \times 10^{-8} \mathrm{mbar}\right)$ and temperature $(260 \mathrm{~K})$. (b) Plot of the logarithm of the steady state reaction rate $R$ for cis-trans isomerization (opens squares) and hydrogenation (open circles) pathways obtained after prolonged exposure with cis-2butene versus the logarithm of the $\mathrm{D}_{2}$ pressure together with linear fits.

and hydrogenation) under steady state conditions. ${ }^{9,31}$ Between the olefin pulses the surface was exposed only to $\mathrm{D}_{2}$ to allow re-saturation of the $\mathrm{Pd}$ particles with $\mathrm{D}_{2}$ prior to the following butene pulse.

Fig. 4 shows the results of pulsed MB experiments carried out at $260 \mathrm{~K}$ for a constant $c i s$-2-butene pressure $\left(p_{\text {cis-2-butene }}=\right.$ $2.7 \times 10^{-8}$ mbar, flux $=5.6 \times 10^{-6}$ molecules $\mathrm{cm}^{-2} \mathrm{~s}^{-1}$ ) and different $\mathrm{D}_{2}$ pressures, varying by a factor of $\sim 13$ and ranging from 0.4 to $5.3 \times 10^{-6}$ mbar. The corresponding

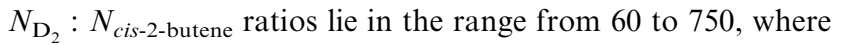
$N_{\mathrm{D}_{2}}$ and $N_{\text {cis-2-butene }}$ are the numbers of $\mathrm{D}_{2}$ and cis-2-butene molecules impinging on the surface per unit time, respectively. In all isothermal experiments discussed in the following, the catalyst was first pre-exposed to a continuous $\mathrm{D}_{2}$ beam $(280 \mathrm{~L})$ to reach saturation and then a sequence of $c i s$-2-butene pulses was applied while the $\mathrm{D}_{2}$ beam remained running. A typical MB sequence included 50 short butene pulses (4 s on, $4 \mathrm{~s}$ off) followed by 30 longer pulses ( $20 \mathrm{~s}$ on, $10 \mathrm{~s}$ off time). Between the olefin pulses the surface was exposed only to $\mathrm{D}_{2}$ to re-saturate the $\mathrm{Pd}$ particles. In all cases reported here, the pulse shape and intensity remained identical for the last 30 long pulses, indicating that the system had reached a quasi steady state behavior. The averages of the last 30 long pulses for both $c i$-trans isomerization product trans-2-butene- $d_{1}$ (upper grey traces) and hydrogenation product butane- $d_{2}$ (lower black traces) are displayed in Fig. 4a for seven different $D_{2}$ pressures studied. Note that the $\mathrm{D}_{2}$ exposure during $10 \mathrm{~s}$ between the butene pulses considerably exceeds the amount of $\mathrm{D}$ atoms required for saturation of $\mathrm{Pd}$ particles.

The steady state reaction rates for both reaction pathways show a linear increase with increasing $\mathrm{D}_{2}$ pressure in the pressure range from 0.4 to $5.3 \times 10^{-8}$ mbar. Fig. $4 \mathrm{~b}$ shows the plots of the steady-state reaction rates for both reaction pathways in double logarithmic coordinates $\ln R$ vs. $\ln p_{\mathrm{D}_{2}}$.
Note that for the hydrogenation reaction pathway the reaction rate does not always reach a constant value at the end of the olefin pulse. In this case, the rate value at the end of the cis-2butene exposure was taken as the quasi steady state reaction rate. According to a general power law, the reaction rate $R$ can be expressed as $R=k p_{\text {butene }}^{n} p_{\mathrm{D}_{2}}^{m}$, where $k$ is the rate constant, $p_{\text {butene }}$ and $p_{\mathrm{D}_{2}}$ are the partial pressures of the reactants, and $n$, $m$ are the formal reaction orders in butene and $\mathrm{D}_{2}$ pressures, respectively. The slope of the curve plotted as $\ln R v s . \ln p_{\mathrm{D}_{2}}$ at constant cis-2-butene pressure gives the formal reaction order $m$ for $\mathrm{D}_{2}$ pressure. The isomerization and hydrogenation reaction pathways exhibit reaction orders of $m_{\mathrm{isom}}=+0.7$ and $m_{\mathrm{hydr}}=+1.0$, respectively, as shown in Fig. 4. These values are in good agreement with the results by Somorjai et $a l .{ }^{13}$ who reported reaction orders close to unity for both isomerization and hydrogenation on $\mathrm{Pd}(111)$. Also for olefin hydrogenation over supported Pd catalysts under ambientpressure conditions, a formal reaction order around unity with respect to the hydrogen pressure is typically observed. ${ }^{3,5,15-20}$

\subsection{Kinetic model}

The obtained formal reaction orders can be rationalized on the basis of a kinetic model which assumes a Langmuir-Hinshelwood reaction mechanism for a low surface coverage and noncompetitive adsorption for 2-butene and $\mathrm{D}_{2}$. We note that the present model is based on the mean field approximation implying homogeneous distribution of the reactive species and the identical activity of all adsorption sites, which cannot be perfectly fulfilled on the Pf nanoclusters. The main purpose of this model is to identify the reaction steps, which can be adequately described in the mean field approximation, and such steps, which deviate from the predictions of the model. This analysis of the deviation allows us to draw conclusions on the structure-sensitivity of the corresponding processes.

In the steady state, the concentrations of the key reaction intermediates $c i s$-2-butene- $d_{0}$ (denoted for simplicity as butene$d 0$ in the kinetic equations) and 2-butyl- $d_{1}$ (butyl- $d 1$ ) are constant, which can be written as:

$$
\begin{aligned}
\frac{\mathrm{d} \theta(\text { butene- } d 0)_{\mathrm{ads}}}{\mathrm{d} t}= & \text { Flux }_{\mathrm{B}} S_{\mathrm{B}}-k_{\mathrm{hydr} \_1}[\text { butene- } d 0][\mathrm{D}] \\
& -k_{\mathrm{des}, \mathrm{B}}[\text { butene- } d 0]+k_{\mathrm{el}}^{\prime}[\text { butyl }-d 1]=0
\end{aligned}
$$

$$
\begin{aligned}
\frac{\mathrm{d} \theta(\text { butyl }-d 1)_{\mathrm{ads}}}{\mathrm{d} t}= & k_{\mathrm{hydr} \_1}[\text { butene- } d 0][\mathrm{D}]-k_{\mathrm{el}}^{\prime}[\text { butyl- } d 1] \\
& -k_{\mathrm{el}}[\text { butyl }-d 1]-k_{\mathrm{hydr} \_2}[\text { butyl- } d 1]\left[\mathrm{D}^{*}\right]=0
\end{aligned}
$$

where [butane- $d 0]$ and [butyl- $d 1$ ] are the steady state surface concentrations of butene- $d_{0}$ and 2-butyl- $d_{1}$, respectively; [D] is the steady state concentration of the surface deuterium species.

Flux $_{\mathrm{B}}$ and $S_{\mathrm{B}}$ are the butene- $d_{0}$ flux and the sticking coefficient, respectively; $k_{\mathrm{hydr} \_1}$ and $k_{\mathrm{hydr} \_} 2$ are the rate constants of the first and the second half-hydrogenation steps (steps 2 and 4 in Fig. 1, correspondingly); $k_{\mathrm{des}, \mathrm{B}}$ is the rate constant for butene- $d_{0}$ desorption; $k_{\mathrm{el}}^{\prime}$ and $k_{\mathrm{el}}$ are the rate constants of $\beta$-hydride elimination for the steps $\left(2^{\prime}\right)$ and (3), correspondingly. 
$\left[D^{*}\right]$ indicates the steady state concentration of a second type of deuterium species, which participates in the second halfhydrogenation of 2-butyl- $d_{1}$ to butane- $d_{2}$. Note that we do not introduce here any assumptions on the exact physical nature of this second type of deuterium species. As was mentioned before, $\mathrm{D}^{*}$ can be either a subsurface $\mathrm{D}$ species or a surface D species for which the adsorption and/or electronic properties are modified by the presence of subsurface D. We assume that under steady state conditions [D*] is directly proportional to the surface concentration of $\mathrm{D}$ with a proportionality factor $\alpha$ :

$$
\left[\mathrm{D}^{*}\right]=\alpha[\mathrm{D}]
$$

If we assume that only a negligibly small fraction of cis-2butene- $d_{0}$ is formed from decomposition of the 2-butyl- $d_{1}$
A correct analytical solution of eqn (4)-(6) is not trivial and lies beyond the scope of this study. To overcome this problem, we can make the assumption that only a negligible fraction of deuterium is consumed by the reaction with hydrocarbons and that the D surface concentration is mainly governed by the adsorption-desorption equilibrium of $\mathrm{D}_{2}$. This assumption can be made since all experiments were carried out at a very large excess of $\mathrm{D}_{2}$ flux with respect to the cis-2-butene flux, with $N_{\mathrm{D}_{2}} /$

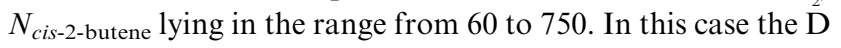
concentration can be expressed as:

$$
[\mathrm{D}]=\left(\frac{\text { Flux }_{\mathrm{D}} S_{\mathrm{D}}}{k_{\mathrm{des}, \mathrm{D}}}\right)^{\frac{1}{2}}
$$

and the reaction rates of cis-trans isomerization and hydrogenation transform to:

$$
\begin{aligned}
& R_{\text {isom }}=\frac{\operatorname{Flux}_{\mathrm{B}} S_{\mathrm{B}} k_{\mathrm{hydr} \_1} k_{\mathrm{el}} \sqrt{\operatorname{Flux}_{\mathrm{D}} S_{\mathrm{D}} / k_{\mathrm{des}, \mathrm{D}}}}{\left(k_{\mathrm{hydr} \_1} \sqrt{\text { Flux }_{\mathrm{D}} S_{\mathrm{D}} / k_{\mathrm{des}, \mathrm{D}}}+k_{\mathrm{des}, \mathrm{B}}\right)\left(k_{\mathrm{hydr} \_2} \alpha \sqrt{\text { Flux }_{\mathrm{D}} S_{\mathrm{D}} / k_{\mathrm{des}, \mathrm{D}}}+k_{\mathrm{el}}^{\prime}+k_{\mathrm{el}}\right)} \\
& R_{\text {hydr }}=\frac{\text { Flux }_{\mathrm{B}} S_{\mathrm{B}} k_{\text {hydr_1 } 1} k_{\mathrm{hydr}_{2} 2} \alpha\left(\operatorname{Flux}_{\mathrm{D}} S_{\mathrm{D}} / k_{\mathrm{des}, \mathrm{D}}\right)}{\left(k_{\mathrm{hydr} \_1} \sqrt{\text { Flux }_{\mathrm{D}} S_{\mathrm{D}} / k_{\mathrm{des}, \mathrm{D}}}+k_{\mathrm{des}, \mathrm{B}}\right)\left(k_{\mathrm{hydr} \_2} \alpha \sqrt{\text { Flux }_{\mathrm{D}} S_{\mathrm{D}} / k_{\mathrm{des}, \mathrm{D}}}+k_{\mathrm{el}}^{\prime}+k_{\mathrm{el}}\right)}
\end{aligned}
$$

species (reaction step $2^{\prime}$ ) relative to the amount of cis-2butene- $d_{0}$ formed from sticking, we obtain the following expressions for the steady state concentrations of the key surface intermediates:

$$
\begin{aligned}
{[\text { butene- } d 0] } & \approx \frac{\operatorname{Flux}_{\mathrm{B}} S_{\mathrm{B}}}{k_{\mathrm{hydr} \_1_{1}[\mathrm{D}]+k_{\mathrm{des}, \mathrm{B}}}} \\
{[\text { butyl- } d 1] } & \approx \frac{\operatorname{Flux}_{\mathrm{B}} S_{\mathrm{B}} k_{\mathrm{hydr} \_1}[\mathrm{D}]}{\left(k_{\mathrm{hydr} \_1}[\mathrm{D}]+k_{\mathrm{des}, \mathrm{B}}\right)\left(k_{\mathrm{hydr} \_2}\left[\mathrm{D}^{*}\right]+k_{\mathrm{el}}^{\prime}+k_{\mathrm{el}}\right)}
\end{aligned}
$$

and the reaction rates of cis-trans isomerization $\left(R_{\text {isom }}\right)$ and hydrogenation $\left(R_{\text {hydr }}\right)$ can be written in the form:

$$
\begin{aligned}
& R_{\text {isom }}=k_{\mathrm{el}}[\text { butyl- } d 1] \\
& \approx \frac{\text { Flux }_{\mathrm{B}} S_{\mathrm{B}} k_{\mathrm{hydr} \_1_{1} k_{\mathrm{el}}[\mathrm{D}]}}{\left(k_{\mathrm{hydr} \_1}[\mathrm{D}]+k_{\mathrm{des}, \mathrm{B}}\right)\left(k_{\mathrm{hydr} \_}\left[\mathrm{D}^{*}\right]+k_{\mathrm{el}}^{\prime}+k_{\mathrm{el}}\right)} \\
& R_{\mathrm{hydr}}=k_{\mathrm{hydr}_{-} 2}[\mathrm{D} *][\text { butyl- } d 1] \\
& \approx \frac{\text { Flux }_{\mathrm{B}} S_{\mathrm{B}} k_{\mathrm{hydr} \_1_{1}} k_{\mathrm{hydr} \_2_{2}}\left[\mathrm{D}^{*}\right] \cdot[\mathrm{D}]}{\left(k_{\mathrm{hydr} \_1}[\mathrm{D}]+k_{\mathrm{des}, \mathrm{B}}\right)\left(k_{\mathrm{hydr}_{2} 2}\left[\mathrm{D}^{*}\right]+k_{\mathrm{el}}^{\prime}+k_{\mathrm{el}}\right)}
\end{aligned}
$$

For deuterium, the condition of a constant surface concentration in the steady state gives:

$$
\begin{aligned}
\frac{\mathrm{d} \theta(\mathrm{D})_{\mathrm{ads}}}{\mathrm{d} t}= & \operatorname{Flux}_{\mathrm{D}} S_{\mathrm{D}}-k_{\mathrm{des}, \mathrm{D}}[\mathrm{D}]^{2}-k_{\mathrm{hydr} \__{-}}[\text {butene- } d 0][\mathrm{D}] \\
& -k_{\mathrm{hydr} \_2}[\text { butyl- } d 1]\left[\mathrm{D}^{*}\right]=0
\end{aligned}
$$

with Flux $_{\mathrm{D}}$ and $S_{\mathrm{D}}$ being the $\mathrm{D}_{2}$ flux and the sticking coefficient, respectively; $k_{\mathrm{des}, \mathrm{D}}$ is the reaction constant for associative desorption of $\mathrm{D}_{2}$.
The obtained dependencies (8) and (9) of the reaction rates on the deuterium flux, which is directly proportional to the pressure, allow us to rationalize the experimentally observed formal reaction orders. For the cis-trans isomerization pathway, if both conditions

$$
k_{\mathrm{des}, \mathrm{B}} \gg k_{\mathrm{hydr}_{-} \cdot[\mathrm{D}]}
$$

and

$$
k_{\mathrm{el}}^{\prime}+k_{\mathrm{el}} \gg k_{\text {hydr_2 }} \alpha[\mathrm{D}]
$$

are fulfilled, the reaction rate depends positively on the deuterium flux with an upper limit for the reaction order 0.5 , which is reasonably close to the experimental value of 0.7 . It should be noted that this limit turns to 1.0 if we assume that $D$ consumption by reaction with hydrocarbons prevails over $\mathrm{D}_{2}$ desorption (see eqn (6)). The intermediate value of 0.7 observed experimentally most likely reflects the fact that both $\mathrm{D}_{2}$ desorption and $\mathrm{D}$ consumption by hydrocarbons contribute to the observed reaction order. However, we note that if (10) and (11) are not fulfilled, either a negative or zero reaction order would be observed for the deuterium pressure.

Given the conditions of (7), (10) and (11), the reaction order for the hydrogenation reaction pathway has an upper limit of 1.0, which coincides with the experimentally obtained value 1.0. In more general terms, the assumptions (10) and (11) mean that the rate of butene desorption (step $1^{\prime}$ ) is fast compared to the rate of the first half-hydrogenation (step 2) and that the rate of $\beta$-hydride elimination of butyl species (steps $2^{\prime}$ and 3 ) is much higher than the rate of its second half-hydrogenation (step 4).

Next, a qualitative analysis of the time dependence of the product response curves allows for interpretation of the mechanistic processes taking place on the surface. Fig. 5 displays the transient reactivity behavior over the duration of 


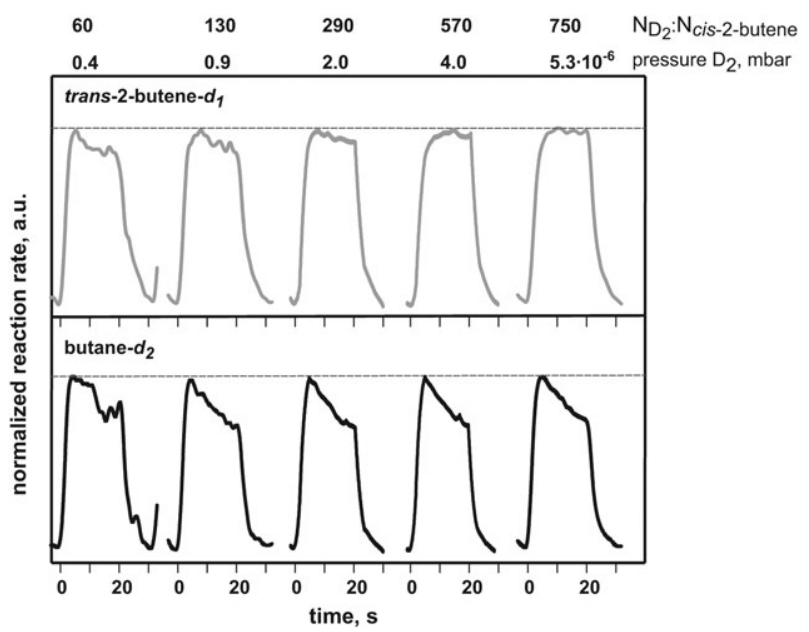

Fig. 5 Normalized averaged reaction rates obtained in the experiments shown in Fig. 4 for selected $\mathrm{D}_{2}$ pressures $(0.4,0.9$ and $5.3 \times 10^{-6} \mathrm{mbar}$ ). Shown are the rates for the isomerization (grey traces) and hydrogenation (black traces) pathways. At the two lowest $\mathrm{D}_{2}$ pressures, the decaying pulse profiles point to $\mathrm{D}$-deficient conditions for both reaction pathways, whereas at the highest $D_{2}$ pressure $\left(5.3 \times 10^{-6} \mathrm{mbar}\right)$ only the hydrogenation rate decreases over the duration of the cis-2-butene pulse (from ref. 32).

the cis-2-butene pulse for the isomerization pathway (upper grey traces) and hydrogenation pathway (lower black traces) for five $\mathrm{D}_{2}$ pressures $0.4,0.9,2.0,4.0$ and $5.3 \times 10^{-6} \mathrm{mbar}$. The pulse heights were normalized to the same value for more convenient examination of the changes in the pulse shape with increasing $\mathrm{D}_{2}$ pressure.

At the highest presented $\mathrm{D}_{2}$ pressure $\left(N_{\mathrm{D}_{2}}: N_{\text {cis-2-butene }}=\right.$ $750, \mathrm{D}_{2}$ pressure $5.3 \times 10^{-6}$ mbar) the reaction rate of cis-trans isomerization displays a rectangular form which follows the time profile of the reactant butene, whereas the hydrogenation pathway shows a high reaction rate at the beginning of the olefin exposure followed by a considerable decrease over the duration of the pulse. As discussed previously, the rectangular form of the response curve attests to equal reaction rates on the initially D-saturated surface (at the beginning of the pulse) and on the surface under the steady state conditions (at the end of the pulse) thus suggesting that the rate is not limited by the availability of deuterium. Consequently, each of the steps (1), (2) or (3) can be potentially rate determining. There is a general agreement in the literature that $\beta$-hydride elimination is fast compared to butyl formation ${ }^{39,40}$ and cannot be the ratelimiting step. In this case, the overall isomerization rate can be limited either by the rate of cis-2-butene adsorption (steps 1 and $1^{\prime}$ ) or by formation of the butyl- $d_{1}$ reaction intermediate (step 2). Based on the analysis of the kinetic model implying that cis-2-butene desorption must be faster than its first half-

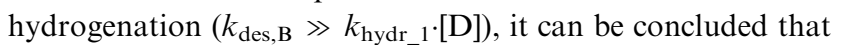
formation of butyl- $d_{1}$ species (step 2) determines the cis-trans isomerization rate under these conditions.

In contrast, the pulse form of the hydrogenation pathway at the same $\mathrm{D}_{2}$ pressure $\left(N_{\mathrm{D}_{2}}: N_{\text {cis-2-butene }}=750, \mathrm{D}_{2}\right.$ pressure $5.3 \times 10^{-6}$ mbar) suggests deuterium deficient conditions, ${ }^{9,31}$ when the availability of $\mathrm{D}$ species is reduced in the steady state (at the end of the pulse) as compared to the D-saturated particles (at the beginning of the pulse). ${ }^{41}$ Note that under all conditions applied in this study, the reaction is carried out in a large excess of $\mathrm{D}_{2}$ in the gas phase with reactant ratios $N_{\mathrm{D}_{2}}: N_{\text {cis-2-butene }}=40-750$, so that the decrease of the reaction rates cannot be explained simply by a stoichiometrically insufficient supply of the gas phase molecular deuterium. Since both the concentration of the butyl- $d_{1}$ intermediate and surface [D] remain constant over the duration of the pulse, as evidenced by the rectangular pulse profile of the isomerization rate, ${ }^{9,31}$ the decreasing hydrogenation rate can be explained most likely by the decreasing availability of a special type of $\mathrm{D}^{*}$ species participating in the second half-hydrogenation step (step 4). Previously, we obtained experimental evidence that this special type of $\mathrm{D}^{*}$ species is associated with $\mathrm{H} / \mathrm{D}$ absorbed in the subsurface region of $\mathrm{Pd}$ nanoparticles, ${ }^{9}$ their exact nature remains, however, not clear. Apparently, such $D^{*}$ species are initially present at the beginning of the pulse on the D-saturated particles, resulting in a high transient hydrogenation rate, but they become depleted during the butene pulse, most likely due to inhibited D diffusion into the subsurface. As a result, their concentration drops to the lower steady state value and the hydrogenation rate decreases. It has to be pointed out that this effect cannot be explained by the depletion of the regular surface $\mathrm{D}$ species adsorbed on the $\mathrm{Pd}$ particles since otherwise a similar decrease of the cis-trans isomerization rate had to be observed (for more details see ref. 9, 30 and 31). In previous studies we demonstrated that the sustained hydrogenation rate can be achieved only if small amounts of carbon were deposited onto the Pd particle prior to the experiment. ${ }^{9,30} \mathrm{We}$ explained this phenomenon by easier hydrogen subsurface diffusion through the surface sites modified by carbon, which allows for maintaining the concentration of subsurface hydrogen species also under steady state reaction conditions. In line with this proposal, essentially barrierless subsurface hydrogen diffusion into the $\mathrm{Pd}$ clusters modified by $\mathrm{C}$ was recently predicted theoretically. ${ }^{33}$

At the lowest $N_{\mathrm{D}_{2}}: N_{\text {cis-2-butene }}$ ratios (60 and $130, \mathrm{D}_{2}$ pressure 0.4 and $0.9 \times 10^{-6}$ mbar), the pulse shape of the cis-trans isomerization rate changes and shows a behavior typical for deuterium deficient conditions, with a higher transient rate on the D-saturated surface than the steady state reaction rate. Apparently, under such conditions even the concentration of surface D species decreases after introduction of butene. The most likely reason for this is inhibition of dissociative deuterium adsorption (step 5 in Fig. 1) by high concentrations of co-adsorbed hydrocarbon species. From the data presented in Fig. 5, the onset for the inhibition of $\mathrm{D}_{2}$ dissociative adsorption on the surface can be estimated in terms of reactant ratio $N_{\mathrm{D}_{2}}: N_{\text {butene }}<290$. Unlike for isomerization, the profile of the hydrogenation rate at the two lowest $N_{\mathrm{D}_{2}}: N_{\text {cis-2-butene }}$ ratios remains essentially the same as for the highest ratio, $N_{\mathrm{D}_{2}}: N_{\text {cis-2-butene }}=750$, attesting to a reduced availability of $\mathrm{D}$ species under steady state conditions as compared to the D-saturated catalyst. Going across the entire $N_{\mathrm{D}_{2}}: N_{\text {cis-2-butene range, the form of }}$ the cis-trans isomerization profile smoothly changes from the non-rectangular one at low ratios to the rectangular one at high $N_{\mathrm{D}_{2}}: N_{\text {cis-2-butene }}$ ratios (Fig. 5). This trend indicates that at low reactant ratios $N_{\mathrm{D}_{2}}: N_{\text {cis-2-butene }}$ (i.e. at low $\mathrm{D}_{2}$ pressures) the 
replenishment rate of surface D species in steady state is insufficient to retain the initial isomerization rate (step 5 in Fig. 1), while at high reactant ratios the replenishment of D is fast under steady state conditions and allows the system to maintain the concentration of $\mathrm{D}$ species at the initially high level.

In contrast, the hydrogenation profiles remain very similar for all investigated $\mathrm{D}_{2}$ pressures. In this pathway, the reaction rate drops by $\sim 30 \%$ from the initial value after 20 s olefin exposure for all reaction conditions. It is important to point out that there is no correlation between the pulse shape of the two reaction pathways: whereas a smooth transition from the D-deficient to D-rich conditions is observed for cis-trans isomerization with increasing $\mathrm{D}_{2}$ pressure, the hydrogenation profile remains the same in the entire pressure region. This observation strongly suggests that the hydrogenation rate is governed by the time evolution of some special kind of $\mathrm{D}$ species, which is not identical to the regular surface species involved in the cis-trans isomerization. This conclusion is consistent with our previous studies recognizing the presence of subsurface D species as a necessary condition for hydrogenation to proceed. $^{9}$ Apparently, the formation/ replenishment of this type of $\mathrm{D}^{*}$ species is slow under all investigated conditions, even when there are no limitations in availability of the surface $\mathrm{D}$ species at the highest $\mathrm{D}_{2}$ pressures (as indicated by the rectangular pulse profiles of the cis-trans isomerization pathway). This conclusion is in line with our previous studies indicating that the presence of subsurface D species is required for hydrogenation. ${ }^{9}$ The fact that the populations of such species decrease even when no limitations in availability of the surface D species are observed indicates that co-adsorbed hydrocarbons must negatively affect diffusion of the surface D species into the subsurface. Apparently, the extent of this inhibition for the formation of subsurface hydrogen species is greater than the hydrocarbon inhibition for formation of surface species. Indeed, for the isomerization pathway, which proceeds with surface $\mathrm{D}$, the transition from D-deficient to D-rich conditions is observed at ratios $N_{\mathrm{D}_{2}}: N_{\text {cis-2-butene }}>290$. In contrast, the hydrogenation route, requiring the presence of the subsurface D species, shows a non-rectangular pulse profile even at a ratio of $N_{\mathrm{D}_{2}}: N_{\text {cis-2-butene }}=750$, indicating slow formation of the subsurface species, which limit the overall hydrogenation rate. The stronger inhibition of subsurface $\mathrm{D}$ formation by hydrocarbon species as compared to surface D most likely originates from different microscopic mechanisms of these processes.

\subsection{Dependence on the cis-2-butene pressure}

Next, a series of isothermal experiments were performed where the influence of the $c i s$-2-butene pressure and the $N_{\mathrm{D}_{2}}: N_{\text {cis-2-butene }}$ ratio on the reactivity of $\mathrm{Pd} / \mathrm{Fe}_{3} \mathrm{O}_{4}$ catalyst was investigated. In these experiments, the $\mathrm{D}_{2}$ pressure was kept constant at $4.0 \times 10^{-6} \operatorname{mbar}\left(f l u x=3.2 \times 10^{15}\right.$ molecules $\cdot \mathrm{cm}^{-2} \mathrm{~s}^{-1}$ ), while the cis-2-butene pressure was varied to three different pressures: $1.2 \times 10^{-8}, 2.7 \times 10^{-8}$, and $41 \times 10^{-8}$ mbar with the corresponding $N_{\mathrm{D}_{2}}>: N_{\text {cis-2-butene ratios lying in the range }}$ from 1280 to 40 . The experiments were carried out at
$260 \mathrm{~K}$ applying the same pulsing scheme as described in section 3.1. Fig. 6a shows the results of pulsed MB experiments carried out at $260 \mathrm{~K}$ for the three different butene pressures. At the lowest butene pressure $\left(1.2 \times 10^{-8} \mathrm{mbar}\right)$, both isomerization and hydrogenation rate exhibit a roughly rectangular pulse shape, following the pulse profile of butene. In contrast, at the highest butene pressure $\left(41 \times 10^{-8}\right.$ mbar $)$ there is an initial instantaneous increase of the reaction rates for both reaction pathways, followed by an abrupt decrease within a few seconds, after which the rates reach steady state. At a butene pressure of $2.7 \times 10^{-8}$ mbar an intermediate behavior is observed: the isomerization rate follows the rectangular pulse form of the reactant, whereas the hydrogenation rate is somewhat higher at the beginning of the butene pulse and decreases during the pulse duration to a lower steady state level.

A qualitative analysis of the product response curves suggests an interpretation for the microscopic processes taking place on the surface. At the lowest butene pressure $\left(1.2 \times 10^{-8}\right.$ mbar, $\left.N_{\mathrm{D}_{2}}>: N_{\text {cis-2-butene }}=1280\right)$, the transient kinetic data show that both isomerization and hydrogenation pathways simply follow the time evolution of the reactant butene, indicating that there is no limitation in D availability for either reaction pathway. Apparently, both reactions can be limited under these conditions either by the rate of $c i s$-2-butene adsorption (step 1) or by formation of the butyl- $d_{1}$ reaction intermediate (step 2); note that $\beta$-hydride elimination is believed to be fast as compared to butyl formation and cannot be the rate-determining step. ${ }^{39,40}$ Following the analysis of the kinetic model described in section 3.1, it is likely that formation of $c i s-2$-butyl- $d_{1}$ is the slowest step in the cis-trans isomerization pathway. In the case of the intermediate cis-2-butene pressure $\left(2.7 \times 10^{-8}\right.$ mbar, $N_{\mathrm{D}_{2}}>: N_{\text {cis-2-butene }}=$ 750 ), the isomerization rate nearly follows the rectangular pulse of the reactant butene, whereas the hydrogenation rate decreases over the olefin pulse indicating D-deficient conditions. As discussed in section 3.1, this behavior suggests that the surface concentration of D species is not dramatically affected by co-adsorbed hydrocarbons under the steady state conditions, whereas the availability of the subsurface D species is reduced in the steady state as compared to the beginning of the pulse when the catalyst was D-saturated. This latter observation attests to effective inhibition of subsurface D diffusion by the co-adsorbed olefins.

At the highest butene pressure $\left(41 \times 10^{-8}\right.$ mbar, $N_{\mathrm{D}_{2}>}: N_{\text {cis-2-butene }}=40$ ), both the isomerization and the hydrogenation pathway show at the beginning of the olefin exposure high reaction rates that considerably decrease over the duration of the olefin pulse. This behavior can be explained most easily by a strong limitation in D availability under steady state conditions for both reaction pathways, i.e. the concentrations of surface and most likely also subsurface D species are considerably affected by co-adsorbed hydrocarbons. Apparently, a high cis-2-butene flux results in the build-up of a relatively high surface concentration of the olefin and its derivatives, which poison the surface and negatively affect the concentration of $\mathrm{D}$, e.g. by inhibition of dissociative adsorption of $\mathrm{D}_{2}$ and/or $\mathrm{D}$ subsurface diffusion. It should be noted, however, that even under these conditions the reaction is carried out in a large excess of $\mathrm{D}_{2}$ in the gas phase 
$\left(N_{\mathrm{D}_{2}}>: N_{c i s-2-b u t e n e}=40\right)$, so that the drastic decrease of the reaction rates cannot be explained simply by a limited supply of molecular deuterium from the gas phase. As a consequence, the dissociative deuterium adsorption (step 5) can be identified here as being inhibited, possibly enough to change the rate-determining step, as will be discussed below.

In line with the results presented in section 3.1, the observed dependency of the product response curves on the butene pressure shows that the hydrogenation pathway is negatively affected at lower olefin pressures than the cis-trans isomerization. Mechanistically, it means that relatively large amounts of hydrocarbons can be adsorbed on the surface without negatively affecting the concentration of the surface D species, the scenario observed at $N_{\mathrm{D}_{2}}: N_{\text {cis-2-butene }}$ ratios higher than 290 (here, lower values $N_{\mathrm{D}_{2}>}: N_{\text {cis-2-butene }}$ correspond to higher butene pressures). In contrast, coadsorbed hydrocarbon species affect the abundance of subsurface D to a much greater extent and already with a reactant ratio of $N_{\mathrm{D}_{2}>}: N_{\text {cis-2-butene }}=750$ an inhibiting effect on the $\mathrm{D}$ subsurface diffusion is observed.

Next, a quantitative comparison of the initial rates in the transient regime and the steady state reaction rates was performed. Fig. 6 shows the initial (Fig. 6b) and the steady state (Fig. 6c) reaction rates for both pathways plotted as a function of the butene pressure. The initial rates were calculated by determining the reaction rate (pulse height) at the point during the pulse at which the catalyst had been exposed to $0.33 \mathrm{~L}$ of butene (the time when this point was reached was dependent on the butene flux used). In cases where a constant reaction rate was not reached over the pulse duration, the reaction rate at the end of the butene pulse was used as the quasi steady state reaction rate. As discussed in section 3.1, the slopes of the curves in Fig. 6 correspond to the formal reaction orders in butene pressure.

For the transient regime, initial reaction rates on the catalyst pre-saturated with deuterium show positive formal reaction orders of $n_{\text {isom }}=+0.7$ and $n_{\text {hydr }}=+0.3$ for the cis-trans isomerization and hydrogenation pathways, respectively (Fig. 6b). Under steady state conditions, the isomerization rate to trans-2-butene- $d_{1}$ was found to depend only weakly on the cis-2-butene pressure, showing a formal positive reaction order of $n_{\text {isom }}=+0.3$. Similarly, the steady state hydrogenation rate nearly does not depend on the olefin pressure and even exhibits a slightly negative reaction order of $n_{\text {hydr }}=-0.15$ (Fig. 6c). These steady state related values are in good agreement with reaction orders reported in classical catalytic studies under ambient-pressure conditions, ${ }^{3,5,13-18}$ which are near zero. It should be noted that the realistic dependence on the butene pressure in a narrow range of reaction conditions can significantly deviate from the formal reaction orders derived for a large pressure interval. Thus, for the two lowest butene pressures, a positive dependence of the hydrogenation rate on the butene flux is observed, which, however, turns negative if one accounts also for the highest investigated butene pressure (Fig. 6c).

The observed formal reaction orders in butene pressure can be rationalized based on the analysis of the Langmuir-Hinshelwood kinetic model described in section 3.1. For the cis-trans isomerization pathway, a reaction order $n_{\text {isom }}=+0.7$ is observed in the transient regime on the D-saturated surface, a value, which is close to the reaction order $n_{\text {isom,model }}=+1.0$ predicted by the model (see eqn (4) and (8) in section 3.1). Apparently, this good agreement reflects the fact that the adsorbed $\mathrm{D}$ does not inhibit butene adsorption (a condition implied by our model) and consequently the transient reaction rate is as expected directly proportional to the number of butene molecules impinging on the surface. However, in the steady state, the formal reaction order in butene considerably decreases to a value of $n_{\text {isom }}=+0.3$ implying a strong deviation from the assumption of low butene coverage and non-competitive butene and $\mathrm{D}_{2}$ adsorption used in the model. The fact that the butene reaction order changes from $\sim 1$ to $\sim 0$ may reflect a change in the rate limiting step, with replenishment of surface D species

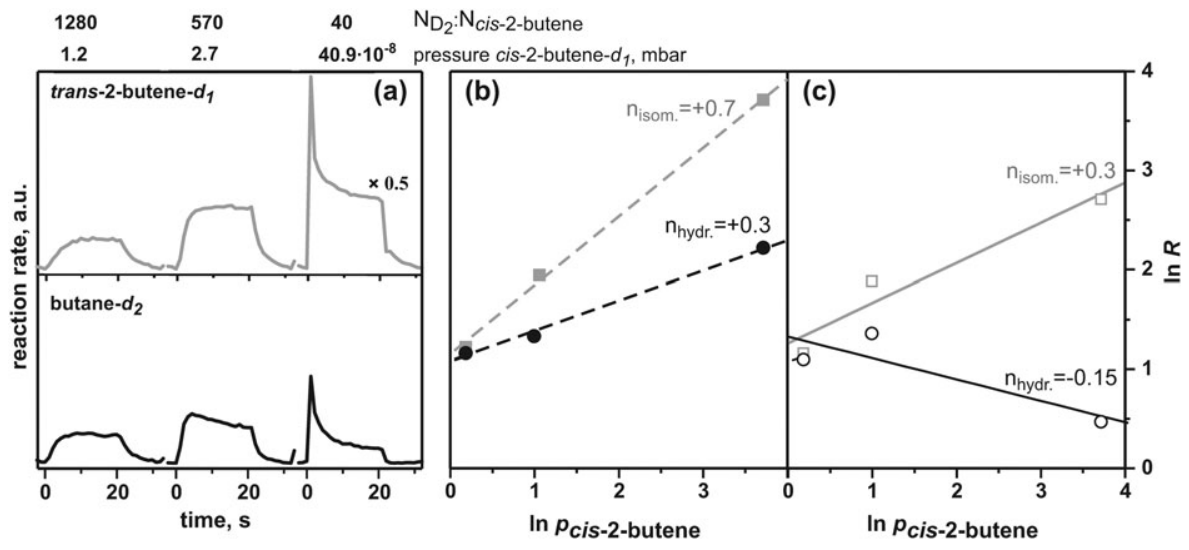

Fig. 6 (a) Averaged reaction rates as a function of time obtained for the $c i s$-trans isomerization (grey traces, product trans-2-butene- $d_{1}$ ) and hydrogenation (black traces, product butane- $d_{2}$ ) pathways from a series of pulsed molecular beam experiments, in which the catalyst was exposed to a continuous $\mathrm{D}_{2}$ molecular beam and the cis-2-butene molecular beam was modulated. The results are shown for the experiments conducted at different cis-2-butene pressures $\left(1.2-40.9 \times 10^{-8} \mathrm{mbar}\right)$ and at a constant $\mathrm{D}_{2}$ pressure $\left(4.0 \times 10^{-6} \mathrm{mbar}\right)$ and temperature (260 K). (b) Plot of the logarithm of the initial reaction rate $R$ for cis-trans isomerization (filled squares) and hydrogenation (filled circles) pathways versus the logarithm of the cis-2-butene pressure together with linear fits. (c) Plot of the logarithm of the steady state reaction rate $R$ for cis-trans isomerization (open squares) and hydrogenation (open circles) pathways versus the logarithm of the cis-2-butene pressure together with linear fits. 
becoming rate limiting. This deviation can be explained by a reduced availability of surface $\mathrm{D}$ species when a steady state concentration of hydrocarbons is established, which results in a much weaker dependence of the reaction rate on the butene pressure. The most likely reason for this is poisoning of the surface by co-adsorbed hydrocarbons, which hamper formation of surface $\mathrm{D}$ species, e.g. by inhibition of dissociative $\mathrm{D}_{2}$ adsorption. This conclusion is in line with the analysis of the product response curves described earlier in this section, where at the highest butene pressure a pronounced non-rectangular pulse profile was observed attesting to a strongly reduced availability of surface D under steady state conditions.

For the hydrogenation pathway, the steady state formal reaction order deviates from the reaction order $n_{\text {hydr,model }}=$ +1.0 predicted by the model (see eqn (5) and (9)) even more than for isomerization. Moreover, it even turns negative under steady state conditions $\left(n_{\mathrm{hydr}}=-0.15\right)$. The last observation strongly suggests that under steady state conditions the surface concentration of hydrocarbon species has a strongly negative affect on the abundance of the D species required for hydrogenation. As with the isomerization, the change in reaction order from $\sim 1$ to $\sim 0$ with respect to butene pressure may reflect a change in the rate-limiting step, with replenishment of D species becoming rate limiting. In view of our previous results identifying the presence of subsurface H/D species as a necessary condition for hydrogenation to proceed, ${ }^{9}$ one can speculate here that the more pronounced effect of coadsorbed hydrocarbons on the hydrogenation pathway can be traced back to a considerably stronger reduction of the abundance of subsurface D as compared to the surface D species. This hypothesis is in line with the qualitative analysis of the product response curves described earlier in this section. For the hydrogenation pathway (see Fig. 6a), even at the intermediate butene pressure ( $\left.p_{\text {butene }}=2.7 \times 10^{-8} \mathrm{mbar}\right) \mathrm{a}$ non-rectangular pulse profile is observed suggesting $\mathrm{D}^{*}$ deficient conditions. Conversely, the concentration of the surface D species is not negatively affected at this intermediate pressure, as indicated by the rectangular profile of the isomerization rate. Only at the highest applied butene pressure is the concentration of the surface D species also reduced by the presence of butene, supporting our hypothesis that the abundance of subsurface D species more sensitively depends on the concentration of hydrocarbons. Microscopically, this phenomenon can be explained by inhibited subsurface $\mathrm{D}$ diffusion in the presence of coadsorbed hydrocarbons.

\subsection{Temperature dependence}

In order to determine the influence of the reaction temperature on cis-trans isomerization and hydrogenation of cis-2-butene, we carried out a series of experiments between 220 to $400 \mathrm{~K}$ keeping the composition of the reactant mixture constant $\left(p_{\text {butene }}=2.7 \times 10^{-8} \mathrm{mbar}, p_{\mathrm{D}_{2}}=4.0 \times 10^{-6} \mathrm{mbar}\right.$, $\left.N_{\mathrm{D}_{2}}: N_{\text {cis-2-butene }}=570\right)$. The pulsed MB experiments were performed in the same way as described in section 3.1. Fig. 7 shows the averages of the reaction rates of the last 30 long pulses for both products trans-2-butene- $d_{1}$ (upper grey traces)

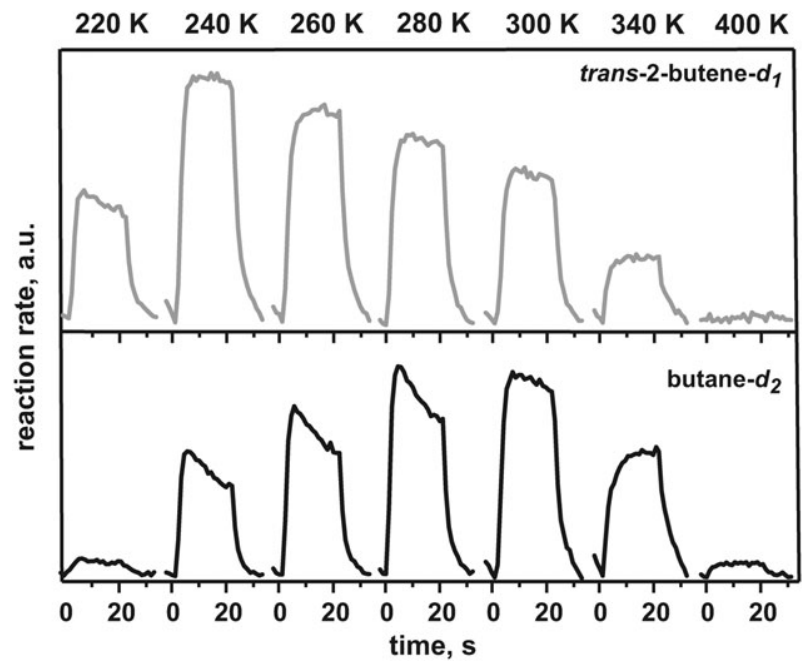

Fig. 7 Averaged reaction rates as a function of time obtained for the cis-trans isomerization (grey traces, product trans-2-butene- $d_{1}$ ) and hydrogenation (black traces, product butane- $d_{2}$ ) pathways from a series of pulsed molecular beam experiments, in which the catalyst was exposed to a continuous $\mathrm{D}_{2}$ molecular beam and the cis-2-butene molecular beam was modulated. The results are shown for experiments conducted at different reaction temperatures $(220-400 \mathrm{~K})$, while the reactant pressures were kept constant $\left(4.0 \times 10^{-6}\right.$ mbar for $\mathrm{D}_{2}$ and $2.7 \times 10^{-8}$ mbar for cis-2-butene).

and butane- $d_{2}$ (lower black traces) at different reaction temperatures.

Both reaction pathways show a non-monotonic dependence on the reaction temperature with a maximum in steady state reaction rate reached at $T_{\max , \text { isomer }}=240 \mathrm{~K}$ for cis-trans isomerization and at $T_{\max , \text { hydrog }}=300 \mathrm{~K}$ for hydrogenation. Note that in the hydrogenation pathway no clear steady state regime could be obtained on the experimental time scale in the temperature range from 240 to $300 \mathrm{~K}$; here, only quasi steadystate rates can be compared, which we define as the rate at the end of the pulse. For cis-trans isomerization, the product response curves exhibit a rectangular shape nearly in the entire temperature range except for the lowest $T=220 \mathrm{~K}$, where a slightly decreasing rate is observed over the duration of the butene pulse. The product response curves of the hydrogenation pathway show a non-rectangular form with a decreasing reaction rate in the temperature range between 220 and $280 \mathrm{~K}$, whereas above $300 \mathrm{~K}$ the pulse form switches to nearly rectangular.

The existence of a maximum in the reaction rates with increasing temperature arises from two counteracting trends: on one hand, the increasing temperature causes a rise of the reaction rate constants, particularly $k_{\mathrm{hydr} \_}$and $k_{\mathrm{hydr} \_}$; on the other hand, the desorption rates of the reactants cis-2-butene and $\mathrm{D}_{2}$ increase, resulting in decreasing coverages [butane- $d 0$ ] and $[D]$. The initial rise of the steady state reaction rates between 220 and $240 \mathrm{~K}$ for isomerization and between 220 and $300 \mathrm{~K}$ for hydrogenation can be ascribed to a predominant growth of the reaction rate constants $k_{\text {hydr_1 }}$ and $k_{\text {hydr_2 }}$. Additionally, faster butene desorption might result in reduced poisoning of the hydrocarbon-covered surface toward dissociative $\mathrm{D}_{2}$ adsorption. In contrast, the decreasing reaction rates at higher temperatures (despite the 
growing reaction rate constants) attest to fast desorption of the reactants that leads to nearly vanishing reactivity at $400 \mathrm{~K}$. The premise of fast desorption of both reactants cis-2-butene and $\mathrm{D}_{2}$ in the investigated temperature region is in good agreement with previous TPD experiments carried out on identical Pd particles. $^{29-31}$ It should be noted that pre-adsorbed D was shown to weaken the binding energy of butene on the surface $^{30,31}$ Therefore the butene coverage [butane- $d 0$ ] can depend in a complex non-monotonous way on the temperature, since faster deuterium desorption (i.e. a lower [D]) leads to an increasing activation barrier for butene desorption.

The most important observation in this series of temperature variation experiments is the different positions of the rate maxima for cis-trans isomerization and hydrogenation, which clearly attest to different rate determining steps for both reaction pathways. Indeed, the rate of the isomerization pathway likely reflects the overall formation rate of the butyl- $d_{1}$ intermediate (as described in section 3.1). In turn, the rate of butyl- $d_{1}$ formation can be limited either by adsorption-desorption equilibrium of cis-2-butene (steps 1 and $1^{\prime}$ ) and/or directly by the rate of the first-half hydrogenation (step 2)-with the effects being dependent on the particular temperature. The temperature dependence of the cis-trans isomerization rate indicates that the surface concentration of butyl- $d_{1}$ species increases up to $240 \mathrm{~K}$ and decreases in the range between $240-400 \mathrm{~K}$. For the hydrogenation pathway, increasing reaction rates are observed up to $300 \mathrm{~K}$ despite the decreasing concentration of butyl- $d_{1}$ species. This fact can be explained only by an even more strongly increasing rate constant for a different rate determining step, which must be the second halfhydrogenation step of butyl- $d_{1}$ to butane- $d_{2}$ (step 4). Consequently it can be inferred that the activation barrier for the second-half hydrogenation of the alkyl intermediate is higher than the activation barrier of the first-half hydrogenation. With this we provide for the first time direct experimental evidence that the second half-hydrogenation step is the rate determining process in olefin hydrogenation up to least $300 \mathrm{~K}$ even in a large excess of $\mathrm{D}_{2}$. This is a very important conclusion of this study, since this point is still under debate in the literature for various transition metals. ${ }^{42-44}$
At a microscopic level, the higher effective activation energy of the second half-hydrogenation step as compared to the first half-hydrogenation can be linked to two phenomena: to a high barrier of the elementary reaction step of $\mathrm{D} / \mathrm{H}$ insertion into the Pd-butyl bond and to activated $\mathrm{D} / \mathrm{H}$ subsurface diffusion. On the basis of our experimental dataset, it appears to be difficult to distinguish between these two possible scenarios and further theoretical calculations are needed to clarify the exact microscopic mechanisms.

The product response curves of the cis-trans isomerization pathway exhibit a rectangular profile nearly in the entire investigated temperature region (except of $220 \mathrm{~K}$ ) indicating D-rich conditions, i.e. a high availability of the surface D species in the steady state. Interestingly, for the hydrogenation pathway a transition from non-rectangular pulse profiles to the rectangular ones is observed at about $280 \mathrm{~K}$. This observation means that up to $280 \mathrm{~K}$, adsorption of hydrocarbons negatively affects the concentration of $D^{*}$ species (associated with subsurface D) resulting in decreasing reaction rates over the butene pulse. However, above $280 \mathrm{~K}$, the negative effect of coadsorbed hydrocarbons on the abundance of subsurface D species vanishes as indicated by similar hydrogenation rates in the transient regime and under steady state conditions. This phenomenon can be explained either by a strong decrease of the butene surface concentration [butane- $d 0$ ] due to fast desorption and/or by an easier replenishment of the subsurface D species. The latter effect might be a consequence of a growing rate constant for subsurface D diffusion or a result of a reduced inhibition of subsurface D diffusion due to a lower steady state concentration of co-adsorbed hydrocarbons.

\subsection{Conversion and selectivity}

Fig. 8 displays the overall conversion and selectivity toward the competing cis-trans isomerization and hydrogenation pathways under the steady state conditions for different reaction conditions. The conversion is calculated as $\frac{R_{\mathrm{isom}}+R_{\mathrm{hydr}}}{\text { Flux }_{\mathrm{B}}}$. The selectivity is presented in terms of the product ratio for the hydrogenation product butane- $d_{2}$ to the isomerization product trans-butene- $d_{1} \frac{R_{\mathrm{hydr}}}{R_{\text {isom }}}$ (further indicated as butane- $d_{2}:$ transbutene- $d_{1}$ ratio). By using such values, we can directly
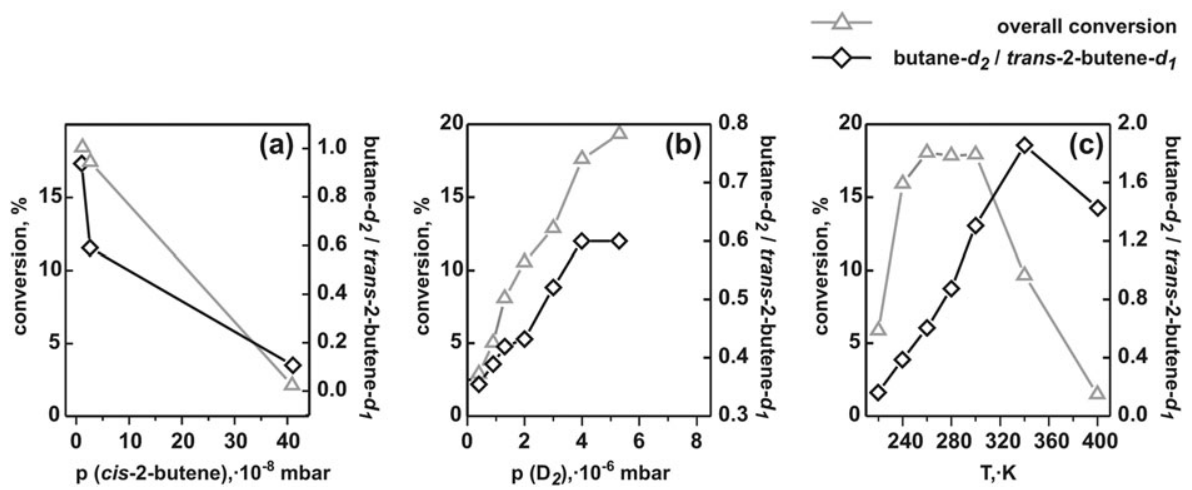

Fig. 8 Displayed is the overall conversion (grey triangles) and the ratio of butane- $d_{2}:$ butene- $d_{1}$ production (black rhombs) as a function of (a) the cis-2-butene pressure (at $260 \mathrm{~K}$ with a $\mathrm{D}_{2}$ pressure of $4.0 \times 10^{-6} \mathrm{mbar}$ ), (b) the $\mathrm{D}_{2}$ pressure (at $260 \mathrm{~K}$ with a cis-2-butene pressure of $2.7 \times 10^{-8}$ mbar) and (c) the temperature (with a $\mathrm{D}_{2}$ pressure of $4.0 \times 10^{-6} \mathrm{mbar}$ and a cis-2-butene pressure of $2.7 \times 10^{-8}$ mbar). The conversion is calculated as $\frac{R_{\text {isom }}+R_{\text {hydr }}}{\text { Flux }_{\mathrm{B}}}$. 
compare the overall activity and selectivity of the model catalytic system investigated in this study under well-defined UHV conditions with the results of catalytic experiments carried out under ambient pressure conditions on realistic catalytic systems prepared under non-UHV conditions. This allows us to draw conclusions on the transferability of the detailed microscopic mechanisms obtained in this study to the processes taking place under more realistic catalytic conditions.

The dependence of the overall conversion and the selectivity on the cis-2-butene pressure is shown in Fig. 8a. With increasing cis-2-butene pressure, both the overall conversion and the butane- $d_{2}$ : trans-butene- $d_{1}$ ratio decrease. As discussed in section 3.2, the decrease of the steady state overall activity can be attributed to limited availability of D in both the surface and subsurface states, which presumably arises from poisoning of the catalytic surface by co-adsorbed hydrocarbons towards dissociative $\mathrm{D}_{2}$ adsorption and $\mathrm{H} / \mathrm{D}$ subsurface diffusion. From our previous discussion it follows that $\mathrm{D}$ diffusion into the subsurface appears to be more negatively affected by co-adsorbed hydrocarbons than dissociative adsorption of $\mathrm{D}_{2}$. This fact is reflected in the highly pronounced drop in the butane- $d_{2}:$ trans-butene- $d_{1}$ product ratio at the two highest applied butene pressures, since formation of butane- $d_{2}$ requires the presence of subsurface D species whereas they are not necessary for the production of trans-butene- $d_{1}$.

Fig. $8 \mathrm{~b}$ shows the overall activity and the product ratio butane- $d_{2}$ : trans-butene- $d_{1}$ as a function of the $\mathrm{D}_{2}$ pressure. Increasing $\mathrm{D}_{2}$ pressures yield an increased overall conversion and the selectivity shifts toward the hydrogenation pathway with the butane- $d_{2}:$ trans-butene- $d_{1}$ ratio growing from $\sim 0.3$ to 0.6 in the investigated pressure region. This observation is in line with the kinetic model described in section 3.1, predicting a stronger dependence of the hydrogenation pathway on the $\mathrm{D}_{2}$ pressure, possibly even more so if subsurface $\mathrm{D}$ facilitates hydrogenation. A similar effect was reported in the ambientpressure studies on olefin conversions over Pd catalysts. ${ }^{15,16,45}$

The temperature dependence of the overall conversion and the selectivity toward hydrogenation $v$ s. cis-trans isomerization is displayed in Fig. 8c. A broad maximum of the total conversion exists between 240 and $300 \mathrm{~K}$, which results from two counteracting trends: first, increasing rate constants $k_{\text {hydr_1 }}$ and $k_{\text {hydr_}} 2$ with increasing temperature and second, decreasing surface coverages of both reactants due to fast desorption at elevated temperatures. The decrease of the overall conversion above $320 \mathrm{~K}$ is in good qualitative agreement with the negative Arrhenius coefficients reported for alkene conversions under ambient-pressure conditions which were previously attributed to facilitated alkene desorption. $5,46,47$

Formation of hydrogenation products is seen to be strongly favored at increasing temperatures with the product ratio butane- $d_{2}$ : trans-butene- $d_{1}$ rising from 0.2 to 2 in the temperature region between $220-360 \mathrm{~K}$. As discussed in section 3.3, two microscopic phenomena can account for such a prominent shift in the selectivity with increasing temperature: a high activation energy of the elementary second half-hydrogenation step from butyl- $d_{1}$ to butane- $d_{2}$ (4) and/or a faster replenishing of the subsurface D reservoir due to an increasing rate constant of the activated D subsurface diffusion. In line with our observations, the catalytic studies on the hydrogenation and isomerization of 1-butene carried out under ambient-pressure conditions report a similar temperatureinduced shift of the selectivity toward hydrogenation for Pd catalysts. ${ }^{5,19}$

Interestingly, for the overall conversion, values of $10-20 \%$ were obtained despite the low absolute reactant pressures applied in this study. These conversion values are much higher than the typical reaction probabilities of $10^{-5}$ to $10^{-10}$ reported for olefin conversions with hydrogen under ambientpressure conditions. ${ }^{3,5}$ One possible explanation is that strong contamination with carbonaceous deposits builds up under typical ambient-pressure reaction conditions, and decreases the active surface area available in practical catalytic systems. On the other hand, the combination of high conversion values together with similar pressure and temperature dependencies for the activity and selectivity justifies the study of these model supported catalysts under low-pressure conditions as suitable proxies for realistic catalytic systems.

\section{Conclusions}

The kinetics of $c i s-2$-butene conversion with deuterium on welldefined $\mathrm{Pd}$ nanoparticles supported on model $\mathrm{Fe}_{3} \mathrm{O}_{4} / \mathrm{Pt}(111)$ film were investigated under UHV conditions employing pulsed isothermal molecular beams. Particularly emphasis was placed on investigation how hydrogen-related processes, such as dissociative adsorption and hydrogen diffusion into the subsurface of nanoparticles, influence activity and selectivity toward cis-trans isomerization and hydrogenation. Pulsed molecular beam experiments allow direct comparison of the reaction rates in the transient regime - on $\mathrm{Pd}$ particles saturated with deuterium - and under steady state conditions in the presence of the reactant butene. The influence of the particular reaction conditions such as the reactant pressures, the $N_{\mathrm{D}_{2}}: N_{\text {cis-2-butene }}$ ratio and the reaction temperature on both initial and steady state reactivity was investigated in a large parameter range.

1. The steady state reaction rates of both the cis-trans isomerization pathway and the hydrogenation pathway increase linearly with $\mathrm{D}_{2}$ pressure with formal reaction orders of $m_{\text {isom. }}=+0.7$ and $m_{\text {hydr. }}=+1.0$, respectively. These values are in good agreement with the reaction orders $m_{\text {isom.,model }}=$ +0.5 and $m_{\text {hydr.,model. }}=+1.0$ predicted by a kinetic model based on a Langmuir-Hinshelwood reaction mechanism in the low-coverage limit.

2. For the cis-trans isomerization pathway, a smooth transition from $\mathrm{D}$-rich to D-deficient conditions with decreasing $\mathrm{D}_{2}$ pressure is observed. The transition to D-deficient conditions takes place at the reactant ratios $N_{\mathrm{D}_{2}}: N_{c i s-2-b u t e n e}<290$. Presumably, co-adsorbed hydrocarbon species negatively affect the $\mathrm{D}$ concentration by inhibition of dissociative deuterium adsorption via surface poisoning. For the hydrogenation pathway, the profiles of the product response curves show decreasing reaction rates almost in the entire investigated pressure region $\left(0.4-5.3 \times 10^{-6}\right.$ mbar) up to a reactant ratio of $N_{\mathrm{D}_{2}}: N_{\text {cis-2-butene }}=750$, even under conditions where cis-trans isomerization proceeds in excess of $\mathrm{D}$. This phenomenon can be ascribed to a strongly decreased population of the subsurface D species, which 
concentration appears to depend more sensitively on the presence of hydrocarbons than the surface D concentration does. Apparently, co-adsorbed butene species negatively affect the abundance of subsurface $\mathrm{D}$, e.g. by inhibiting subsurface diffusion.

3 . The formal reaction order of the cis-trans isomerization pathway with respect to the butene pressure, $m_{\text {isom. }}$, strongly depends on the reaction conditions: whereas in the transient regime $m_{\text {isom. }}$ is +0.7 , under the steady state conditions $m_{\text {isom. }}$. decreases to +0.3 . A similar behavior is observed for the hydrogenation pathway with reaction orders of $m_{\text {hydr. }}=$ +0.3 and -0.15 for the transient and steady state regimes, respectively. The near zero reaction orders strongly deviate from the unity predicted by the kinetic model and can be ascribed to a strongly negative effect of adsorbed olefins on the concentration of all types of $\mathrm{D}$ species. This conclusion was also corroborated by analysis of the product response curves.

4. Both reaction pathways show a non-monotonic dependence on the reaction temperature with a maximum in steady state reaction rate reached at $T_{\text {max,isomer }}=240 \mathrm{~K}$ for cis-trans isomerization and at $T_{\text {max,hydrog }}=300 \mathrm{~K}$ for hydrogenation. It can be concluded that different elementary reaction steps determine the overall reactivity for cis-trans isomerization and hydrogenation. For hydrogenation, second half-hydrogenation of butyl- $d_{1}$ limits the overall rate up to $300 \mathrm{~K}$. The cis-trans isomerization rate is governed either by the butene adsorption-desorption equilibrium or by the first halfhydrogenation of butene. The activation energy of the second half-hydrogenation step was concluded to be higher than for first half-hydrogenation, presumably due to an intrinsically higher activation barrier for $\mathrm{H} / \mathrm{D}$ insertion into the metal-carbon bond.

5. With increasing cis-2-butene pressure, a decrease of the overall activity is observed and the selectivity shifts toward the cis-trans isomerization pathway, which can be attributed to the inhibition of $\mathrm{D}$ formation due to poisoning of the catalyst's surface by co-adsorbed hydrocarbons. At increasing $\mathrm{D}_{2}$ pressures, the overall conversion increases and the hydrogenation pathway is favored most likely due to the stronger dependence of the hydrogenation rate on $\mathrm{D}$ concentration. Increasing temperatures result in a selectivity shift toward hydrogenation, which is connected to the higher overall barrier for the hydrogenation pathway.

6. The observed kinetics are in good agreement with the previous ambient-pressure studies, suggesting that the reaction carried out under UHV conditions on model catalysts can serve as a proxy for olefin conversions with hydrogen at practically relevant pressures.

\section{Acknowledgements}

The authors would like to thank Prof. H.-J. Freund and Prof. R. J. Madix for valuable discussions. SS thanks the Robert Bosch Foundation.

\section{References}

1 T. I. Taylor, in Catalysis, ed. P. H. Emmett, Reinhold, New York, 1957, vol. 5, pp. 257-403.

2 C. Kemball, in Advances in Catalysis and Related Subjects, ed. D. D. Eley, P. W. Selwood and P. B. Weisz, Academic Press, New York, 1959, vol. 11, pp. 223-262.
3 J. Horiuti and K. Miyahara, Hydrogenation of Ethylene on Metallic Catalysts, Report NSRDS-NBC No. 13, National Bureau of Standards, 1968.

4 G. A. Somorjai, Introduction to Surface Science Chemistry and Catalysis, John Wiley \& Sons, New York, 1994.

5 G. C. Bond, Metal-Catalysed Reactions of Hydrocarbons, Springer Science, New York, 2005.

6 F. Zaera, Prog. Surf. Sci., 2001, 69, 1.

7 I. Lee and F. Zaera, J. Catal., 2010, 269, 359.

8 A. M. Doyle, Sh. K. Shaikhutdinov, S. D. Jackson and H.-J. Freund, Angew. Chem., Int. Ed., 2003, 42, 5240.

9 M. Wilde, K. Fukutani, W. Ludwig, B. Brandt, J.-H. Fischer, S. Schauermann and H.-J. Freund, Angew. Chem., Int. Ed., 2008, 47, 9289.

10 A. Valcarcel, F. Morfin and L. Piccolo, J. Catal., 2009, 263, 315.

11 M. Wilde, K. Fukutani, W. Ludwig, B. Brandt, J.-H. Fischer, S. Schauermann and H.-J. Freund, Angew. Chem., 2008, 120, 9430.

12 D. Teschner, J. Borsodi, A. Wootsch, Z. Révay, M. Hävecker, A. Knop-Gericke, S. D. Jackson and R. Schlögl, Science, 2008, 320, 86.

13 C. Yoon, M. X. Yang and G. A. Somorjai, J. Catal., 1998, 176, 35.

14 J. P. Boitiaux, J. Cosyns and S. Vasudevan, Appl. Catal., 1983, 6, 41.

15 S. P. Bressa, O. M. Martinez and G. F. Barreto, Ind. Eng. Chem. Res., 2003, 42, 2081.

16 D. Tetschner, E. Vass, M. Hävecker, S. Zafeiratos, P. Schnörch, H. Sauer, A. Knop-Gericke, R. Schlögl, M. Chamam, A. Wootsch, A. S. Canning, J. J. Gamman, S. D. Jackson, J. McGregor and L. F. Gladden, J. Catal., 2006, 242, 26.

17 K. S. Sim, L. Hilaire, F. Le Normand, R. Touroude, V. Paul-Boncour and A. Percheron-Guegan, J. Chem. Soc., Faraday Trans., 1991, 87, 1453.

18 H. Öner and F. Zaera, J. Phys. Chem. B, 1997, 101, 396.

19 G. C. Bond and J. M. Winterbottom, Trans. Faraday Soc., 1983, 65, 2779

20 S. Hub, L. Hilaire and R. Touroude, Appl. Catal., 1988, 36, 307.

21 J. Horiuti and M. Polanyi, Trans. Faraday Soc., 1934, 30, 1164.

22 F. Zaera, Chem. Rev., 1995, 95, 2651.

23 I. Lee and F. Zaera, J. Am. Chem. Soc., 2005, 127, 12174.

24 R. J. Koestner, J. C. Frost, P. C. Stair, M. A. Van Hove and G. A. Somorjai, Surf. Sci., 1982, 116, 85.

25 F. Zaera, Langmuir, 1996, 12, 88.

26 X.-C. Guo and R. J. Madix, J. Catal., 1995, 155, 336.

27 N. Vasquez, Jr. and R. J. Madix, J. Catal., 1998, 178, 234.

28 A. M. Doyle, Sh. K. Shakhoutdinov and H.-J. Freund, Angew. Chem., Int. Ed., 2005, 44, 629.

29 A. M. Doyle, Sh. K. Shakhoutdinov and H.-J. Freund, J. Catal., 2004, 223, 444.

30 B. Brandt, J.-H. Fischer, W. Ludwig, J. Libuda, F. Zaera, S. Schauermann and H.-J. Freund, J. Phys. Chem. C, 2008, 112, 11408.

31 B. Brandt, W. Ludwig, J.-H. Fischer, J. Libuda, F. Zaera and S. Schauermann, J. Catal., 2009, 265, 191.

32 W. Ludwig, A. Savara and S. Schauermann, Dalton Trans., 2010, 8484.

33 K. M. Neyman and S. Schauermann, Angew. Chem., Int. Ed., 2010, 49, 4743.

34 J. Libuda, I. Meusel, J. Hartmann and H.-J. Freund, Rev. Sci. Instrum., 2000, 71, 4395.

35 T. Schalow, B. Brandt, M. Laurin, D. Starr, Sh. K. Shaikhutdivov, J. Libuda and H.-J. Freund, Catal. Lett., 2006, 107, 189.

36 W. Weiss and W. Ranke, Prog. Surf. Sci., 2002, 70, 1.

37 C. Lemire, R. Meyer, V. Henrich, S. K. Shaikhutdinov and H.-J. Freund, Surf. Sci., 2004, 572, 103.

38 T. Schalow, B. Brandt, M. Lurin, S. Schauermann, J. Libuda and H.-J. Freund, J. Catal., 2006, 242, 58.

39 I. Lee, F. Delbecq, R. Morales, M. A. Albiter and F. Zaera, Nat. Mater., 2009, 8, 132.

40 F. Zaera, Catal. Lett., 2003, 91, 1.

41 Note that the shown pulse profiles are the average of 30 independent nearly identical pulses, i.e. after the interruption of the olefin exposure the deuterium beam restores the surface to it's original highly reactive state. Therefore the decreasing reaction rate over the olefin pulse cannot be associated with irreversible changes of the surface such as e.g. contamination.

42 I. Lee and F. Zaera, J. Phys. Chem. B, 2005, 109, 2745.

43 F. Zaera, J. Phys. Chem., 1990, 94, 8350.

44 F. Zaera, J. Phys. Chem., 1990, 94, 5090.

45 C.-B. Hwang, Y.-S. Fu, y.-L. Lu, S.-W. Jang, P.-T. Chou, C. R. C. Wang and S. J. Yu, J. Catal., 2000, 195, 336.

46 G. C. Bond, Catalysis by Metals, Academic Press, London, 1962.

47 H.-P. Koh and R. Hughes, J. Catal., 1974, 33, 7. 